\title{
CIENFUEGOS: UN EMBLEMA DE LUZ Y OSCURIDAD
}

Los vientos de cambio que arrasaron los muros del Antiguo Régimen no soplaron en una sola dirección. Contra el evangelio revolucionario predicado por los pontífices de la Enciclopedia se alzaron las voces airadas de la reacción europea. En España, donde las ideas ilustradas se difundieron con una rapidez que los esfuezos conjuntos de la Iglesia y la Corona no consiguieron contener, se desencadenó una batalla cuya violencia no amainaría en dos siglos. "Cambio" y "Reforma" fueron las llamadas de clarín de una nueva generación de pensadores que se vieron obligados a trocar la paz, el bienestar y la libertad individual de un día por la promesa de un mañana mejor. No sólo los filósofos y los políticos (uno piensa en Olavide, por ejemplo) sino también dramaturgos, poetas y libreros unieron su voz al coro que cantaba un mundo nuevo. Recurramos de nuevo a los tratados, poemas y dramas de Leandro Fernández de Moratín, Juan Meléndez Valdés, Gaspar Melchor de Jovellanos y Manuel José Quintana, etc.; su lectura nos dejará profundamente conmovidos por el entusiasmo con que se lanzan hacia ese nuevo mañana ${ }^{1}$. Que diferían $-y$ a veces violentamente- unos de otros en cuanto a la manera de renovar la patria es obvio; estas diferencias fomentaron un clima de división y a veces de antagonismo. Pero no hay un espíritu ilustrado al que no anime un profundo ideal de reforma: la era del cambio había llegado y su presencia domina la época. Pero entre tantos renovadores uno de ellos se distingue por la progresiva violencia de su compromiso, de su entrega; habiendo comenzado su carrera de pensador y poeta con la moderación propia del filósofo dieciochesco, su energía le hará lanzarse hacia las ideas nuevas con una creciente fuerza que llegaría a ser legendaria. Quintana recuerda que él pronunció las frases más heroicas que jamás salieron de labios espa-

1 Véanse las obras ya clásicas de Jean SaRRailh, La España ilustrada de la segunda mitad del siglo xviii, F.C.E., México, 1957; RICHARD HERR, España y la revolución del siglo xviii, Aguilar, Madrid, 1964; Vicente Palacio ATARD, Los españoles de la llustración, Guadarrama, Madrid, 1964; ANTONIO Domínguez ORTIZ, La sociedadi española en el siglo xviii, Siglo XXI, Madrid, 1973; y LuIs SÁnchez AgESTA, El pensamiento político del despotismo ilustrado, Instituto de Estudios Políticos, Madrid, 1953. 
ñoles; y $\tan$ heroicas, puesto que, literalmente, pondría su vida en juego en defensa de su idea. Me refiero, naturalmente, a Nicasio Álvarez Cienfuegos, cuya vida y obra describen una trayectoria fascinante que lo lleva de poeta pastoril a redactor de la Gaceta de Madrid, de ilustrado a anti-francés, de estudiante en Salamanca a guerrero intelectual en Madrid y por fin a exiliado en Francia ${ }^{2}$. Intentaré analizar algunos puntos claves de esta trayectoria que nos ayuden a comprender mejor esta figura tan trágicamente representativa del mundo de transición en que vivió y murió.

Cienfuegos creía en el poder unificador de la palabra. De joven pensó que la humanidad acogería con benevolencia el lenguaje que como artista forjaba, y que ese lenguaje contribuiría a encaminarla hacia las metas deseadas. En 1799, con motivo de su discurso de recepción en la Real Academia Española, propuso al augusto cuerpo ciertas ideas que ya había expresado el año anterior en la primera edición de sus Poesías ${ }^{3}$. Ideas y versos se iluminan recíprocamente, y ambas pueden ayudarnos a entender cómo el lánguido poeta bucólico que fue el Cienfuegos adolescente pudo concluir su vida en un trágico y solitario exilio; tan solitario, en efecto, y tan olvidado, que ni del lugar de su tumba ha quedado memoria. Sorprendentemente, ese destino aparece ligado a la concepción de Cienfuegos de la palabra como "signo", como un instrumento que, ordenando el pensamiento, lo prepara para la acción:

Porque los signos y las cosas significadas, las voces y los pensamientos se corresponden necesariamente y corren siempre la misma fortuna. Fijar el sentido de una palabra no es otra cosa sino deslindar el pensamiento de que es signo; compararla con otras es comparar entre sí los pensamientos, ejercitar el juicio; determinar los lugares que deben ocupar las voces en el discurso, esponer en orden las ideas ${ }^{4}$.

La palabra es, pues, el vehículo de la energía del pensamiento; proclama ante la Academia que "la palabra es la pintura vocal del pensa-

2 JOAQUín ARGE hace notar que "Luzán y Cienfuegos abren y cierran emblemáticamente un entero mundo de actividad versificadora, de poesía que en general puede resultar ingrata, pero que configura una de las etapas más inquietas, más nerviosas en la búsqueda, menos felices quizás en los resultados. Las corrientes, las actitudes diversas y hasta contrastantes, en aras de un ideal poético que obedece a los dictámenes de la razón, son visibles como en ningún otro momento" (La poesia del siglo ilustrado, Guadarrama, Madrid, 1980, p. 142). Para la biografía de Cienfuegos, véanse E. PIÑEYRo, "Cienfuegos"', BHi, 11 (1909), 31-54; J. Simón Díaz, "Nuevos datos acerca de Nicasio Álvarez de Cienfuegos', Revista de Bibliografía Nacional, 5 (1944), 263-284; Poesías, ed. José Luis Cano, Castalia, Madrid, 1969. 611-616.

3 J. L. CAno, "Cienfuegos en la Academia", CuH, 94 (1973), núms. 280/282,

4 Cienfuegos, "Discurso", en Memorias de la Academia Española, Rivadeneyra, Madrid, 1870, t. 1, pp. 354-355. Sobre el lenguaje en sus poesías, véanse J. ARCE y A. Cervantes, "Cienfuegos's linguistic ideas", RNo, 19 (1978-79), 49-54. 
miento" 5 , pero ese pensamiento no es un agregado de ideas cualquiera, es un sistema de conceptos que se dirige obsesivamente hacia la generación, mediante un cambio profundo, de un mundo mejor. El discurso repite conceptos claves que ya había formulado en las Poesías, conceptos que introducen en España (al menos con una nueva coherencia) los grandes tópicos que dominarían la revolución francesa ("los vínculos de la humanidad", "las virtudes", "estrecha fraternidad", "hermano", etc.) y que servirían como la " "pintura vocal" de su propio pensamiento. Su visión es ingenua y noble: ingenua porque en ocasiones idealiza desmesuradamente el pasado clásico que presenta como modelo de la futura sociedad libre:

Si uno de los atletas, tal vez acalorado, profería alguna expresión, no injuriosa, que eran incapaces de tal exceso, sino un tanto descomedida, pasaba la disputa, los ánimos se serenaban, la voz del arrepentimiento clamaba en el corazón del culpado, y volaba, con las lágrimas en los ojos, a pedir perdón a su hermano, que ya no se acordaba, o que siempre había ignorado su ofensa ${ }^{6}$,

pero noble porque jamás duda que valga la pena luchar por tal utopía.

Cienfuegos concebía la sociedad nueva como una comunidad de intereses unida por vínculos fraternales. Las academias y sociedades literarias eran microcosmos que reflejaban aquella sociedad más amplia ("unas mismas inclinaciones deben hermanarlos"), y en esta sociedad el más fuerte debe ayudar al más débil:

Conocimientos, opiniones, sistemas, todas las ideas de los particulares deben ser comunes de todo el cuerpo; y de esta comunidad resultará que la actividad y el ardor de uno dará fuego a la tibieza del otro, la ciencia de aquél se aumentará con la de éste, el talento del primero se multiplicará por los de sus hermanos, y el ingenuo, remontado en las alas de una emulación gloriosa, volará rápido de verdad en verdad, de descubrimiento en descubrimiento, de causa en causa, y el término de su vuelo será el triunfo de la razón humana. Aquí no dicta leyes la fuerza. . .?

Ésta es la sociedad ideal de Cienfuegos: fraternal, comunal, racional -o sea, una sociedad impregnada de libertad, igualdad y fraternidad. El poeta extiende su abrazo fraternal más allá de las fronteras de España y más allá del lenguaje español. Se pregunta:

¿Cuándo llegará el día de la razón en que, persuadidos de que todos los hombres somos hermanos, nos gloriemos de la prosperidad de las otras naciones como si fuera propia nuestra, en que el amor de la patria no sea

5 "Discurso", p. 354

6 Ibid., pp. 352-353.

7 Ibid., p. 353. 
opuesto a la humanidad, en que no haya extranjeros, en que nos miremos todos como naturales de una patria común, que es la tierra?

Y concluye su discurso confirmando que la palabra misma será el elemento unificador de la humanidad:

De esta manera, cultivando nuestra lengua al paso que cultivan la suya los otros pueblos, todos se prestarán de día en día nuevos auxilios, se hermanarán más y más, vendrán a ser como una sola; y la virtud, fiando la seguridad de su trono a las armas de la razón, vendrá a ser señora universal del mundo entero ${ }^{9}$.

José Luis Cano acierta cuando escribe que "Cienfuegos era un enamorado de las nuevas ideas que habían puesto de moda los enciclopedistas franceses: la igualdad, la fraternidad universal, el amor a la virtud y al progreso"'10

Esta utopía racional y humana no difiere mucho de aquella socie dad de amigos de Salamanca en que se formó Cienfuegos y que se vt reflejada en sus versos ${ }^{11}$. Las mismas notas de humanidad y hermandad - lo que llamó Quintana su "ilusión de la filantropía más exaltada"12- se repiten con frecuencia. Para él la pregunta esencial es: ¿cómo llegar a la creación de un mundo racional donde la humanidad, la fraternidad e incluso la igualdad reinen? Cienfuegos nunca abraza totalmente la posición elaborada por los franceses de 1789 , y si por el año 1798 expresa a la Real Academia la idea de una unificación a través de semejanzas lingüísticas, en sus poesías sugiere una solución intermedia entre la revolución abierta, copia del ejemplo del norte de los Pirineos, y una unidad utópica a la que se llega en virtud de la bondad intrínseca del hombre.

Como ha demostrado Cano, Cienfuegos era un "poeta social", que manifestaba no sólo un "apasionado humanitarismo" sino también una "inquietud revolucionaria" 13 . Esta "inquietud revolucionaria" se halla en sus versos antes de aparecer en su vida, y creo que podemos considerar a Cienfuegos, al igual que a su amigo Quintana, como un revolucionario a regañadientes. Nos ha mostrado Albert Dérozier que Quintana era uno de los revolucionarios más apasionados de su época ${ }^{14}$,

8 Ibid., p. 362.

9 Ibid., p. 365.

${ }^{10} \mathrm{~J}$. L. CANO, "Cienfuegos, poeta social", en Heterodoxos y prerrománticos, Júcar, Madrid, 1975, p. 85.

${ }^{11}$ E. Alarcos, "Cienfuegos en Salamanca", BRAE, 18 (1931), 712-730; C. Real DE LA RIVA, "La escuela poética salmantina del siglo xVIII", BBMP, 24 (1948), $321-364$

12 Manuel José Quintana, "Literatura", en Obras completas, Hernando, Madrid, 1889 , p. 156

${ }^{13} \mathrm{~J}$. L. Cano "Cienfuegos, poeta social", op. cit., p. 85.

14 Albert Dérozier, Quintana y el nacimiento del liberalismo en España. Turner, Madrid, 1978. 
pero incluso él confesó que vistió el manto de la revolución con sentido del deber, no como un deseo espontáneo. Escribió en su Memoria: "Mi estado, pues, era feliz sin más penas ni desazones que las que llevaba consigo la condición humana. Así, en vez de desear una revolución para aventajarme, todo lo tenía que temer de ella, si llegaba a suceder". Y continúa: "deseaba que sucediese en [mi Patria] una reforma que la sacase del fango vergonzoso en que estaba sumergida; pero no en los términos con que se había hecho en Francia, cuyo mal éxito debía escarmentar hasta a los más temerarios"'15.

Cienfuegos, de joven, compartió con Quintana esta misma resistencia a la revolución violenta. Sus primeras poesías, aunque convencionalmente anacreónticas y pastoriles, sugieren ya aquellos valores que marcarán su obra. En "Mi destino", donde escribe sobre la sangre y la guerra mucho más gráficamente de como lo solían hacer sus antecesores como Nicolás Fernández de Moratín o José Cadalso, ruega "que no siga inhumano, / de polvo y sangre tinto / los bárbaros pendones / de Marte vengativo" 16 y expresa su deseo de que "amante aquél le forme; / éste, oficioso amigo, / y entre los dos le críen / humano y compasivo" (53-56). Esta nota de humanidad y sencillez es fortísima en todo el pensamiento de Cienfuegos; es más, parece estar plenamente consciente de las consecuencias de un mundo en que la humanidad no domina. En "La desconfianza," aunque las palabras se refieren directamente a su amante Filis, pinta un apocalipsis-en-breve, una visión de lo que sería un mundo sin compasión:

En pos, el maduro otoño, mostrando su faz risueña, hará que el lánguido estío bajo sus pámpanos muera. Más el aquilón bramando se arrojará de las sierras, y, lanzando estéril yelo, cubrirá de horror la tierra. Así, la lóbrega noche sucede a la luz febea, la risa a los lamentos, y a los placeres las penas.

Es el universo entero una inconstancia perpetua. .

Una de sus declaraciones más claras contra una sociedad en que triunfa la tiranía sobre la razón se encontrará en su elogio de la deseada

${ }^{15}$ M. J. Quintana, "Memoria sobre el proceso y prisión de don Manuel José Quintana en 1814", en Quintana revolucionario, M.E. Martínez Quinteiro, ed., Narcea, Madrid, 1972, p. 45.

16 Poesias, ed. cit., vv. 33-36. Todas las citas vienen de esta edición y los versos se darán entre paréntesis en el texto. 
“Paz entre España y Francia en 1795", en que expresa su horror ante un mundo en el que las naciones viven en continua discordia. "¡Cuál rechina / el carro horrible do el cañón sentado / va de viudez y de orfandad preñado!” (19-21), grita con repugnancia, y luego pregunta: “ ¿Do está la humanidad, el don divino / que en nuestras almas al nacer imprime / la natura?'" (27-29). Estas notas sombrías se encadenan a lo largo de toda su poesía. Con frecuencia se han considerado como meras expresiones de una angustia prerromántica, pero son, sin duda, algo más profundo. No son exclamaciones que broten de un dolor individual, que expresen el sollozo íntimo de un espíritu reconcentrado, sino que Cienfuegos se hace portavoz de un sufrimiento social; su grito encarna y expresa una auténtica solidaridad y fraternidad con el dolor de los oprimidos, de los siervos, en una palabra, refleja la vivencia de esos ideales de libertad e igualdad sobre los que escribe. Este espíritu fundamentalmente democrático contrasta plenamente con la perspectiva de los primeros ilustrados (piénsese en Feijoo, por ejemolo), pero encaja bien con el nuevo espíritu de transición entre el fin del siglo dieciocho y los comienzos de un siglo nuevo.

La gran virtud ilustrada, la amistad, cobra en Cienfuegos un valor nuevo. Ese "amor que hermana el hombre / con sus iguales" en " $\mathrm{Mi}$ paseo solitario en primavera", es un sentimiento revolucionario pues, fundiendo la fraternidad con la igualdad, adquiere nada menos que un poder nivelador. Todavía no es una fuerza política, pero sí un poder íntimo que puede adquirir en cualquier momento dimensiones sociales. Cienfuegos ruega a los "Ciegos humanos, / sed felices, amad: que el orbe entero / morada hermosa de hermanal familia / sobre el amor levante a las virtudes / un delicioso altar" (99-103) y esta relación familiar se extiende a su creencia utópica de que "en cada humano / un padre encontraréis y un tierno amigo" (125-126). Tal amistad se convertirá en un lazo fraternal: "Tal vez un día la amistad augusta / por la ancha tierra estrechará sus almas / con lazo fraternal" (139-141); y, cuando la amistad se funde con un amor fraternal, se generaliza y se trueca en un impulso social. En el poema "A un amigo en la muerte de un hermano" (94-95) comienza con un tono íntimo: “¿Hay pena igual a la de oír al triste / sufrir sin esperanza?”, pero en seguida, considerando la maldad de los poderosos, concluye que sólo un lazo fraternal puede establecer la unidad y la paz que anhela. "Vive, sí, vive; que si el hado impío / pudo romper sus fraternales lazos, / hermanos mil encontrarás doquiera: / que amor es hermandad, y todos te aman"' (145-148). Dérozier ha notado que también en sus dramas Cienfuegos se pone al lado de los inocentes ${ }^{17}$, y subraya en particular su tratamiento del

17 A. Dérozier, op. cit., p. 120. Lo que escribe Dérozier de Quintana se le puede aplicar con igual justicia a Cienfuegos: "Quintana siente profundamente el malestar social de España en los últimos años del reinado de Carlos IV”, p. 25. 
inocente oprimido en Idomeneo (1792), Zoraida (1798) y La condesa de Castilla $(1802)^{18}$.

En el poema "A un amigo que dudaba de mi amistad", Cienfuegos claramente subraya su ya expresada creencia en el carácter común de la amistad. En primer lugar, la naturaleza misma forma parte del lazo fraternal: "Ahora que el abril con blando aliento / despierta a amor, y en su hermanal cadena / enlaza el hombre recreando el mundo" (25-27). Pero pasa inmediatamente a presentarla como un tipo de argamasa social, un parentesco de individuos que forma una entidad más grande y más sólida: "Yo soy unión, la unión es vida, / la desunión es caos, muerte, nada" (108-109). Y la etapa final llega cuando el poeta revela su naturaleza profundamente revolucionaria en estos versos en que la fraternidad llega a ser no sólo una frontera contra el caos, sino una fuente de poder. Su grito de guerra dice:

["] Mas solo ¿qué podrás? venid, humanos, volad a reuniros, sed hermanos del que solo no basta a su ventura; que en la suya la vuestra se asegura". El hombre obedeció, y en el arado nació la sociedad. Allí, abrazado del hombre el hombre, por la vez primera toda la humanidad sintió en su pecho, toda, toda su esencia, su alma entera, hombre fue el hombre (169-178).

El fundamento, pues, del pensamiento de Cienfuegos es su creencia en la hermandad del hombre. En público —en sus Poesías de 1798 y en su Discurso de 1799 - alude sobre todo a la posible transformación pacífica, especialmente mediante esa concepción individual y social de la amistad como energía niveladora. Pero privadamente, sobre todo en su conocido poema "En alabanza de un carpintero llamado Alfonso" (que no publicó en su edición de 1798, pero que circuló de mano a mano en manuscrito), adoptó una postura más radical y llegó a recomendar soluciones más revolucionarias. Es en este poema donde las amistades diáfanas de la antigüedad clásica, de la Europa renacentista y hasta de la escuela salmantina, fueron transformadas por los ecos de los violentos gritos de "fraternité" que llegaban de las barricadas de París. Cienfuegos los recogió y, aunque a mediados de los años 90 no estaba dispuesto a repetirlos públicamente, les dio forma en sus escritos. $\mathrm{Al}$ llegar el nefasto año de 1808, sin embargo, estará dispuesto, no sólo a expresarlos, sino a defenderlos con su vida.

"En alabanza de un carpintero llamado Alfonso" es un poema sor-

18 La defensa de la soberanía de un pueblo noble y humano se ve claramente en Zoraida. Por ejemplo, Almanzor protesta de la tiranía del rey Boabdil y le pregunta " ¿Por ventura la voz de seis ancianos / Más solemne será que la de un pueblo? / [ . . .] Seis jueces, Boabdil, los compra el oro, / Mas no puede comprar a todo un pueblo"' (I, vii). 
prendente. La poca información de la vida temprana de Cienfuegos que nos ha llegado no nos prepara para esta postura tan desafiantemente radical, y los críticos posteriores que se escandalizaron por el profundo republicanismo del poema (como Hermosilla) o por su postura subversiva (como Menéndez Pelayo) tenían muchísima razón para ello. El poema capta aquellos vientos de revolución a que me referí anteriormente. Menéndez Pelayo temía al siglo dieciocho y siempre sospechó que el pensamiento ilustrado era heterodoxo: su inquietud llegaba inevitablemente a la crisis y la reforma. Y aunque Ortega consideró el siglo dieciocho el menos español de toda la historia española, hasta quejarse de su "ausencia" ("nos ha faltado el gran siglo educador"'19), el ejemplo de un Cienfuegos prueba lo equivocado que estaba.

Cano ha trazado la influencia de Rousseau y de su prohibido Discurso sobre el origen y fundamentos de la desigualdadientre los hombres en la tertulia de Salamanca ${ }^{20}$. Sus ideas de igualdad, fraternidad universal y amor a la virtud se expresaron, se recibieron, se integraron y se presentaron a las generaciones venideras. Quintana se dio cuenta de las lecciones que él había aprendido de Cienfuegos y en 1813 escribió un prólogo conmovedor a las Poesías póstumas de su amigo:

De ti aprendí a no hacer de la literatura un instrumento de opresión y de servidumbre [. . .] ¿Y quién, en la miserable época que acaba de pasar, ha observado mejor que tú esas máximas sagradas? A la vista y casi en las garras del despotismo insolente y bárbaro que nos oprimía cantabas tú las alabanzas de la libertad; y en medio de la corrupción más estragada y del desaliento más pusilánime que hubo nunca, tu voz vehemente y severa nos llamaba poderosamente a la energía de los sentimientos patrióticos y a la sencillez y dulzura de las costumbres inocentes ${ }^{21}$.

Estas "alabanzas de la libertad" son precisamente lo que canta con tanta emoción en su poema a Alfonso.

Este poema es a la vez una consecuencia lógica del pensamiento de Cienfuegos y una anomalía en su obra poética. Es uno de los más extensos - contiene 279 versos- y es, sin embargo, uno de sus poemas más sencillos. El poder de esta obra surge lentamente hasta envolver al lector con su fuerza y emoción devastadora. La posición de Cienfuegos es inequívoca desde el principio. Incluso el epígrafe, una cita sacada de Séneca - "Virtutem. . invenies. . .callosas habentem manus" ("La virtud se encuentra en manos que tienen callos")- ', establece el tono del poema entero. La intransigencia de la posición autorial se subraya en un primer verso: "Yo lo juré: mi incorruptible acento / vengará la virtud, que lagrimosa / en infame baldón yace indigente" (1-3).

19 José Ortega y Gasset, "El siglo XVIII, educador", en Obras de José Ortega y Gasset, Espasa-Calpe, Madrid, 1943, t. 1, p. 623

20 José Luis Cano, "Un prerromántico: Cienfuegos", op. cit., p. 61.

21 Ibid., p. 62. 
El poema presenta las dicotomías tradicionales de palacio / choza, maldad / bondad, riqueza / pobreza, corrupción / nobleza, etc., pero Cienfuegos lleva estos temas más allá de sus fronteras tradicionales y añade dicotomías nuevas. La que tiene mayor interés es la de poder / supresión de libertades. Esto es, el poema salta inmediatamente de un plano especulativo, donde el poeta expone conceptos abstractos y filosóficos, a un plano social y concreto, donde obliga al lector a participar en el ejemplo de un alma atropellada. La demolición de la nobleza que subraya la primera parte del poema y establece el enaltecimiento del humilde carpintero, Cienfuegos la lleva a cabo no sólo temática sino también lingüísticamente. Cienfuegos se dirige a sus "nobles magnates" en la segunda persona del plural, no para personificarlos, ni ponerlos en un plano más íntimo, ni para identificarse con ellos, sino para mofarse de ellos. "Nobles magnates, que la humana esencia / osasteis despreciar por un dorado / yugo servil. . ." (9-11). Retiene su respeto en sus palabras y en la forma que da a esas palabras: "Osasteis"; su democratización agresiva se extiende incluso al lenguaje que emplea: " $\mathrm{Mi}$ lira desoíd" - exige, y subraya su desdén anafóricamente- "vuestra ascendencia / generación del crimen laureado, / vuestro pomposo funeral imperio, / vuestro honor arrogante, / yo los detesto" (12-15). "Yo los detesto" no es sentimiento que se espera de un poema lírico, pero el poder y el ritmo del poema goloean - como las herramientas de Alfonso- con una fuerza lírica arrolladora.

El crescendo aumenta y Cienfuegos interpone la primera sugerencia de lo que puede servir de contrabalance a la agresividad y la pompa de los Tiberios de este mundo. "OOh congojosa / choza del infeliz! a ti volaron / la justicia y la razón desde que fiero, / ayudando al humano, / de la igualdad triunfó el primer tirano" (20-24). "Justicia", "razón," "igualdad": aquí tenemos los valores que Allonso representará, y que Cienfuegos detenderá poderosamente en su verso - y más tarde, con su vida misma. La igualdad se combina con la fraternidad universal, que también aparece temprano en el poema. Cienfuegos pregunta, con tanta convicción como fuerza retórica, " ¿ternamente / habemos de ignorar que el sempiterno / es Padre universal?"' (35-37). Esta igualdad (o en realidad la falta de ella) es simplemente una "verdad" para Cienfuegos (41), una verdad usurpada por falsas distinciones de riqueza y poder, un poder que hizo proclamar al noble: "Soy más; a los sudores / el cielo te crió: tú en la pobreza, / yo en rico poderío, / tu destino es servir, mandar el mío" (45-48). Para Cienfuegos, quien adopta una posición muy roussoniana, tales actitudes contradicen las verdaderas leyes del orden natural; son "transtornadores / de las eternas leyes de natura" (50-51) ${ }^{22}$. Lo que deja aparte el infame rico no es sólo su riqueza sino su negativa a considerar a todos los homores como sus her-

22 Véase R. Froldi, "Natura e società nell'opera di Cienfuegos", AFLM, 21 (1968), 43-86. 
manos. Esta negación del lazo fraternal humano es, para el poeta, imperdonable, y una transgresión injustificable de la voluntad de Dios. El noble trata de justificar su arrogancia sugiriendo que su poder procede de Dios. La respuesta de Cienfuegos no deja ninguna duda:

$$
\begin{aligned}
& \text { ¿Nobles serán los pocos pensamientos } \\
& \text { de un ser que innatural huella inferiores } \\
& \text { de sus hermanos, y que audaz procura } \\
& \text { en sobrehumana esfera } \\
& \text { divinizar su corrupción grosera? }(52-56)
\end{aligned}
$$

No sin causa escribe Cano que "las imprecaciones contra los nobles son violentísimas" 23 .

Dado todo lo anterior, el lector cree que el poeta va a incitar a su héroe a rebelarse, a sacudir el yugo de su opresión, como lo habían hecho sus hermanos en París unos años atrás. Tal creencia no sería demasiado injustificada. Y no hay que olvidar que el precedente ya se había establecido. Pero Cienfuegos fue un revolucionario a pesar de sí mismo, como lo fue su amigo Quintana, y las armas de Alfonso no iban a ser la espada o la escopeta, sino el formón y el escoplo. Alfonso no aspira ni a la riqueza ni al poder, sino al respeto, a la igualdad y a la tolerancia. Su escoplo será su Excalibro, su "apoyo. . .y firme abrigo / contra el hambre y maldad" (101-102). Estas palabras prefiguran los sentimientos expresados por otro poeta español de siglo y medio más tarde, que tuvo también que exiliarse y morir, como Cienfuegos, en Francia: como escribió Antonio Machado a la muerte de su amigo y maestro Francisco Giner de los Ríos, "Yunques sonad, enmudeced campanas'. La divinidad de la virtud, que antes Cienfuegos había acusado a los ricos de haber usurpado groseramente, ahora pertenece al hombre humilde. La igualdad y la justicia no son sólo derechos humanos sino también divinos. La asociación entre Cristo y Alfonso queda explícita. Dios comenta "éste es el hombre que crió mi mano" (152), y Cienfuegos nos hace recordar que en este otro carpintero, el humilde Alfonso, se encuentra "la imagen de Dios, Dios en la tierra" (160).

Sin embargo, Cienfuegos resiste a la tentación de ofrecer una mera canción de elogio a la dignidad humana, la justicia y la igualdad. Su poema no acaba con coros de hosanas ni con gritos de ardor revolucionario (como lo haría Quintana, por ejemplo, en "A Juan de Padilla" o "El Panteón del Escorial"), sino con una triste sencillez que es infinitamente más devastadora y por ello más profundamente conmovedora. Alfonso, enfermo, cansado y sin protección, muere. Su viuda y sus hijos huérfanos ${ }^{24}$ son su único testamento. Cienfuegos creía, como hemos

23 J. L. Cano, "Cienfuegos, poeta social", op. cit., p. 96.

24 El tema de la orfandad tiene un lugar central en la poesía de Cienfuegos. ¿Será que los recuerdos de su propia juventud tenían algo que ver con sus profundos deseos de fraternidad universal? 
visto, que "la palabra es la pintura vocal del pensamiento" y sus últimas palabras en este poema reflejan, sin lugar a dudas, la esencia de su cuadro mental:

Tú la inocencia
me enseñarás: lo honesto y virtuoso
leeré en tu oscuridad: harás que fuerte
sepa amar el afán y la indigencia;
y que allí atrincherado
huelle el poder del crimen entronado (274-279).

Si ésta fue su visión, ¿qué podría hacer para realizarla? ¿Cómo puede un individuo transformar sus palabras en acciones? ¿Es necesario hacerlo? Es trágicamente irónico que las circunstancias históricas forzarían a Cienfuegos a transformarse en su propio Alfonso. $\mathrm{Y}$ al realizar esta transformación, llegó a ser un emblema de las corrientes de pensamiento y emoción que chocan en este período tumultuoso. La información biográfica recogida por José Luis Cano nos lo revela. Dos historias bastan para demostrar cómo las acciones simples y angustiadas de don Nicasio le ponen al lado de su humilde carpintero. Cano cuenta la primera historia con gran sensibilidad. Se trata de los días tan difíciles de mayo de 1808, cuando, gravemente enfermo, Cienfuegos tuvo que presentarse ante Murat para calmar la ira del general francés por haberse publicado en la Gaceta de Madrid dos noticias de un carácter (para el régimen intruso) subversivo. Según Cano, aunque los sucesos del dos de mayo sorprendieron a Cienfuegos enfermo en la cama, seguía dirigiendo la Gaceta. Allí publicaba una noticia procedente de Reus el 23 de abril sobre la proclamación de Fernando VII como Rey de España. "Esta noticia [. . .] era un claro desafío al Generalísimo Murat, Jefe Supremo del ejército francés de ocupación en Madrid". Una segunda noticia, también publicada por Cienfuegos en la Gaceta del día 3, se refería a la proclamación en León, "y el tono era aun más desafiante" 25 .

Cano continúa narrando que Murat insistió en que Cienfuegos se presentara en su despacho, amenazándole con fusilamiento si no publicaba en la Gaceta una rectificación. Cienfuegos sabía que con ello se jugaba la vida, pero se negó a cumplir la orden. "Ante la amenaza de muerte que pesaba sobre el poeta, sus compañeros, los Oficiales de la Secretaría de Estado, presentaron su dimisión en pleno, solidarizándose con su actitud' '26. Cienfuegos luego pidió y recibió una licencia por razones de salud y se apartó de la Gaceta.

La segunda historia está relacionada con la primera, y la cuenta el buen amigo de Cienfuegos, el poeta Quintana. Es corta, pero capta concisamente la actitud de Cienfuegos y nos deja con una idea no sólo del

25 Poesias, ed. cit., pp. 23-24.

26 Ibid., pp. 24-25. Véase también, del mismo autor, "Cienfuegos durante la invasión francesa", $M J S$, t. 1, 167-176. 
hombre Cienfuegos sino también de la profunda admiración que inspiró en los otros. Quintana, como Cienfuegos, un hombre intensamente patriótico, recuerda que le habían pedido defender a los afrancesados, una petición que rechazó rotundamente: "Me viene a la memoria escribe luego en su Memoria sobre el proceso y prisión- que pocos días después encontrándome con Cienfuegos, a quien habían hecho la misma proposición y encontrado la misma repulsa, dándonos cuenta recíproca de nuestra aventura, concluyó con decirme: Nosotros hemos hecho lo que debiamos, venga después lo que quiera: una vez se muere y no más'" ${ }^{27}$. Esta frase, de deslumbrante y heroica fuerza, sintetiza el espíritu de la época y pone a Cienfuegos dentro del marco conceptual de los que luchaban contra la tiranía intelectual y política. Son conceptos a la vez únicos y universales porque captan las corrientes y los conflictos en que se vieron envueltos los hombres que vivían en una España que atravesaba cambios importantísimos. Como ha demostrado Javier Herrero en su brillante estudio sobre Los origenes del pensamiento reaccionario en España, la confrontación entre las ideologías contrarias formuladas a mediados del siglo dieciocho formó la base de lo que vino a llamarse el mito de "las dos Españas". Los mensajes articulados por los campeones del pensamiento reaccionario se integraron en una teoría de conspiración univesal que consideraba cualquier deseo de defender conceptos como la libertad, la fraternidad universal, la igualdad, la tolerancia, la resistencia a la tiranía y el apoyo de una nueva estructura para el pacto social como impulsos que se proponían destruir el statu quo y realizar un nuevo orden. Y, evidentemente, ése era el fin a que estos movimientos se dirigían. Alfonso y su escoplo amenazaron el statu quo. Lo que temían más los reaccionarios - una nueva estructura social- era inevitable, y en la primera década del siglo xix llegó a ser, por lo menos teóricamente, una realidad. Herrero no es el único en señalar la gravedad de estos problemas. Sabemos conclusivamente por documentos propuestos por algunos especialistas ${ }^{28}$ que se trataba de asuntos de la más honda seriedad. Según Herrero, hay varias imágenes clave que forman el mito fundamental del argumento contra la Ilustración. Éstas se agrupan alrededor de la existencia de una "conspiración universal", cuyas fuerzas - el Bien y el Mal- se organizan en el siglo xviII en una triple conspiración: la conspiración de los filósofos, que adoran la razón para destruir la fe; la conspiración de los jansenistas, que apoyan "el

27 M. J. Quintana, “Memoria. . ", pp. 53-54

28 Véanse principalmente GonZalo AnEs, El Antiguo Régimen, los Borbones, Alianza, Madrid, 1975; Miguel Artola, La burguesía revolucionaria (1808-1869), Alianza, Madrid, 1973; IRIS M. ZAVALA, Clandestinidad y libertinaje erudito en los albores del siglo xviii, Ariel, Barcelona, 1978; MARIA G. ToMsich, El jansenismo en España, Siglo XXI, Madrid, 1972; Joel SaugnieuX, Le jansénisme espagnol du xviiie siècle, Gátedra Feijoo, Oviedo, 1975; GABRIEL LoveTT, Napoleon and the birth of modern Spain, New York University Press, New York, 1965; José A. Ferrer Benimeli, La masonería española del siglo xviii, Siglo XXI, Madrid, 1974. 
satánico ideal" de la libertad dentro de la Iglesia misma; y la conspiración masónica, que bebe en las fuentes de la razón, los derechos humanos y la libertad;

es más, los masones han comenzado a realizar en sus logias una sociedad en la que se borran las clases sociales, atacando así el orden natural querido por Dios. Esas tres conspiraciones se reunieron a fines del siglo XVIII y se propusieron la destrucción de la civilización europea, mediante la revolución universal que comenzó en Francia, en 1789. Los movimientos liberales, las democracias parlamentarias, no son sino los medios de que Satán se vale para realizar tan diabólica empresa ${ }^{29}$.

Ahora bien, Cienfuegos no participó abiertamente en "conspiraciones", ni mucho menos en pactos con Satán; ni se le acusó directamente de tal cosa; como escribe Cano, "aunque era evidente su ideología enciclopedista, Cienfuegos se veía obligado a ser prudente en su conducta pública'" 30 . Sin embargo, su vida y sus actitudes fueron representativas de aquéllos contra quienes tales ataques se dirigían, y su defensa de la razón, la libertad, los derechos humanos y la igualdad social, le situó justamente en el campo de batalla entre las fuerzas de la luz y las fuerzas de la oscuridad. Según Dérozier, "Quintana, Somoza, Gallego, bajo la égida de su maestro Cienfuegos, consiguen romper los lazos que retenían prisioneros a sus compatriotas. Luchan contra un mundo paralizado. Rechazan las viejas obligaciones. Aprenden y enseñan el sentido de la libertad"'31. Creía con absoluta convicción en los ideales que presentaba en sus escritos y, no obstante, nunca buscó aquella actitud heroica. Lentamente transformó sus palabras de fraternidad universal en acciones que subrayaron sus creencias. Como Dickens nos haría recordar más tarde, era el mejor de los tiempos y el peor de los tiempos, pero con más frecuencia era el peor de los tiempos para los que luchaban a favor del cambio. Su vida intelectual cabe dentro de dos fechas claves - la Revolución Francesa de 1789 y las liberales Cortes de Cádiz de 1810 - y sus obras exhalan las aspiraciones de toda una generación que fue testigo del proceso trágico y difícil por el que Europa y España tuvieron que pasar. Y por eso fue el destino de Cienfuegos morir en el exilio y casi en el olvido, lejos de la tierra que sus palabras y sus hazañas quisieron con tanta pasión enaltecer e iluminar.

David T. Gies

University of Virginia.

29 JAVIER Herrero, Los orígenes del pensamiento reaccionario español, Cuadernos para el Diálogo, Madrid, 1971, pp. 23-34.

30 J. L. Cano, "Cienfuegos, poeta social", op. cit., p. 90.

31 A. DÉrozier, op. cit., p. 25. 